\title{
Good Mental Health in Old Age is A Real Possibility
}

\author{
Roberto Volpe ${ }^{1^{*}}$, Gianluca Sotis ${ }^{1}$, Stefano Predieri ${ }^{2}$ and Massimiliano Magli ${ }^{2}$ \\ ${ }^{1}$ The Italian National Research Council (CNR), Rome, Italy \\ ${ }^{2}$ The Italian National Research Council (CNR), Bologna, Italy
}

"Corresponding author: Roberto Volpe, The Italian National Research Council (CNR), Rome, Italy, E-mail: roberto.volpe@cnr.it

Received date: December 27, 2016; Accepted date: January 17, 2017; Published date: January 19, 2017

Copyright: (C) 2017 Volpe R, et al. This is an open-access article distributed under the terms of the Creative Commons Attribution License, which permits unrestricted use, distribution, and reproduction in any medium, provided the original author and source are credited.

\section{Short Communication}

Kenneth Rockwood recently wrote about health expectations in old age, calling into question the dichotomy between increased life expectancy and the prevalence of disability in older people, and an increase in medical expenses [1].

From a policy standpoint, a growing elderly population has become a challenge to our society. However, we maintain we can be moderately optimistic, because cognitive impairment, or worse, dementia, are not always caused by Alzheimer's disease or are the consequence of major ischemic or haemorrhagic stroke. They are often due to micro-infarcts and/or micro-haemorrhages ("mini-strokes") at the level of small, cerebral vessels, which can cause alterations in brain mass. These may be detected using magnetic resonance imaging (MRI), as white matter hyperintensities, cerebral microbleeds, lacunar infarcts or enlarged perivascular spaces, and lead to cognitive impairment and memory loss [2].

Moreover, cerebrovascular disease and Alzheimer's disease often coexist. It has been estimated that between 60 to $90 \%$ of patients with Alzheimer's have cerebrovascular disease [3]. Systematic analysis has, in fact, shown that the risk factors for atherosclerosis are also risk factors for Alzheimer's disease [4]. Conversely, the Honolulu-Asia Aging Study [5] has demonstrated that if we do not have high blood pressure, hyperglycaemia, hypercholesterolemia and hypertriglyceridemia (and if we receive correct nutritional and lifestyle information), we have a good chance of living long, healthful lives, free not only from physical dysfunction but also from cognitive impairment.

Therefore, if vascular disease is a major cause of (vascular) dementia, by treating cardiovascular risk factors such as atrial fibrillation, arterial hypertension, hyperlipidemia, diabetes, smoking, physical inactivity, alcohol abuse, obesity and sleep apnea, we have a window of opportunity to prevent and reduce dementia in older people [6-9]. In addition, we must not only treat cardiovascular risk factors, but must also monitor our patients to ensure continued compliance. Patients that are highly compliant and adhere to their prescribed medical therapy are at a significantly lower risk of cardiovascular events compared to those who are non-compliant [10].

This said, during an era of budget cuts and economic crisis, when attention is focused on the overall cash balance and one strategy to achieve this is to cut expenditure on medication, we should at least attempt to optimize the efficiency of health strategies which are not so expensive. One long-standing strategy points in this direction: prevention based on a healthy lifestyle. Moderate, regular physical activity and a healthy diet can also have a beneficial effect on brain structure and activity and, consequently, on cognition [11]. This is because while an unhealthy diet increases the risk of cardiovascular disease and other non-communicable diseases such as osteoporosis, neurodegenerative diseases and some types of cancer [12], a wellbalanced diet reduces the risk of developing type 2 diabetes, cardiovascular disease, cancer, Parkinson's disease and Alzheimer's disease, and has been shown to maintain a longer telomere length - a biomarker of longevity $[13,14]$.

When we talk of a healthy diet we are talking above all about the "Mediterranean" diet (MD), a dietary regime associated with lower cardiovascular risk and lower total mortality consistent across diverse geographic regions and pre-specified patient subgroups $[15,16]$. This diet is low in saturated fatty acids and cholesterol, and rich in monounsaturated fatty acids (found in extra virgin olive oil), in omega-3 fatty acids (found in fish and nuts), in non-refined carbohydrates and fibres with a low glycaemic index, in vegetable proteins and in antioxidants, such as vitamins and polyphenols. Monounsaturated fatty acids and omega- 3 in particular, maintain the structure of neural cells, while antioxidants play a significant role in the prevention or attenuation of pathologies associated with redox imbalance, such as atherosclerosis and other chronic degenerative diseases.

In other words, the MD contains a large number of "functional foods" - foods that contain substances which provide medical or health benefits. And we should not forget that adherence to the MD is linked to the tradition of how people sourced, enjoyed and savored their food, turning every meal into an occasion for a socializing with friends and family and the fact that they often spent time outdoors getting sun and fresh air. This is one of the factors which determines the longevity of the Japanese and Mediterranean populations and counteracts agerelated cognitive decline.

This is the approach that we are following in the EWHETA (Eat Well for a HEalthy Third Age) Project. Aging is accompanied by changes in food consumption, either voluntary or imposed by health issues, and as a result of alterations in sensory acuity, which affect taste and smell and may lead to disaffection for eating with the subsequent risk of malnutrition. In fact, nutritional depletion is a significant factor in adverse long-term health effects. Therefore, considering that nutrition is a major factor in the state of health of ageing people, our goal has been to develop a novel food ("Mediterranean Lasagna") that is nutritionally well balanced and can be considered "complete" in terms of its nutritional profile (calories, whole carbohydrates, vegetable proteins, vegetable fats, vitamins, mineral salts) so that it can be consumed as a "complete meal" followed only by a portion of fruit. It is easy to heat up; easy to eat even if there are difficulties of mastication due to dental problems; cheap and tasty. To achieve the desired results, the project involves older people in designing their novel food, based on past food preferences and present needs and constraints. Besides the individual benefit of taking part in an enjoyable, educational activity, participants are the first to taste and rate the recipes intended for consumers of their same age groups. By encouraging the enjoyment 
Citation: Volpe R, Sotis G, Predieri S, Magli M (2017) Good Mental Health in Old Age is A Real Possibility. J Aging Sci 5: 168. doi: 10.4172/2329-8847.1000168

Page 2 of 2

of food, reawakening perception and the senses, we can increase eating motivation and food-related health gains in old age.

Hippocrates said, "If nutrition and physical activity are inadequate, the body gets sick". We believe that through proper nutrition and regular moderate physical activity we can not only increase life expectancy, but also mental, cognitive and physical health and wellbeing, at the same time, containing health expenditure. In conclusion, we believe that the great goal of longevity without decrepitude is possible.

\section{References}

1. Rockwood K (2016) What we can expect of health in old age? Lancet 387: 730-731.

2. Heath CA, Mercer SW, Guthrie B (2015) Vascular comorbidities in younger people with dementia: a cross-sectional population-based study of 616245 middle-aged people in Scotland. J Neurol Neurosurg Psychiatry 86: 959-964.

3. Kalaria RN (2000) The role of cerebral ischemia in Alzheimer's disease. Neurobiol Aging 21:321-330.

4. Casserly I, Topol E (2004) Convergence of atherosclerosis and Alzheimer's disease: inflammation, cholesterol, and misfolden proteins. Lancet 363: 1139-1146.

5. Launer LJ, Hughes T, Yu B, Masaki K, Petrovitch H, et al. (2010) Lowering midlife levels of systolic blood pressure as a public health strategy to reduce late-life dementia: perspective from the Honolulu Heart Program/ Honolulu Asia Aging Study. Hypertension 55: 1352-1359.

6. Biessels GJ (2014) Capitalizing on modifiable risk factors for Alzheimer's disease. The Lancet Neurol 13: 752-753.
7. Fillit H, Nash DT, Rundek T, Zuckerman A (2008) Cardiovascular risk factors and dementia. Am J Geriatr Pharm 6: 100-118.

8. Hachinski V, World Stroke Organization (2015) Stroke and potentially preventable dementias proclamation: updated World Stroke Day proclamation. Stroke 46: 3039-3040.

9. Ngandu T, Lehtisalo J, Solomon A, Levälahti E, Ahtiluoto S, et al. (2015) A 2 year multidomain intervention of diet, exercise, cognitive training, and vascular risk monitoring versus control to prevent cognitive decline in at-risk elderly people (FINGER): a randomised controlled trial. Lancet 385: 2255-2263.

10. Laufs U, Retting-Ewen V, Bohm M (2011) Strategies to improve drug adherence. Eur Heart J 32: 264-268.

11. Norton S, Matthews FE, Barnes DE, Yaffe K, Brayne C (2014) Potential for primary prevention of Alzheimer's disease: an analysis of populationbased data. The Lancet Neurol 13: 788-794.

12. Arnold M, Pandeya N, Byrnes G, Renehan AG, Stevens GA, et al. (2014) Global burden of cancer attributable to high body-mass index in 2012: a population-based study. Lancet Oncol 16: 36-46.

13. Grant WB (1997) Dietary links to Alzheimer's disease. Alzheimer's Dis Rev 2: 42-55.

14. Crous-Bou M, Fung TT, Prescott J, Julin B, Du M, et al. (2014) Mediterranean diet and telomere length in Nurses' Health Study: population based cohort study. Br Med J 349: g6674.

15. Sofi F, Abbate R, Gensini GF, Casini A (2010) Accruing evidence about benefits of adherence to Mediterranean diet on health: an updated systematic review with meta-analysis. Am J Clin Nutr 92: 1189-1196.

16. Estruch R, Ros E, Salas-Salvado J, Covas MI, Corella D, et al. (2010) Primary prevention of cardiovascular disease with Mediterranean diet. N Engl J Med 368: 1279-1290. 